\title{
Fosfito de potássio não protege plantas de milho contra os efeitos fitotóxicos do glyphosate ${ }^{1}$
}

\author{
Giovanna Larissa Gimenes Cotrick Gomes ${ }^{2}$, Edivaldo Domingues Velini² ${ }^{2}$ Caio Antonio Carbonari ${ }^{2}$
}

\begin{abstract}
Potassium phosphite does not protect maize plants against the phytotoxic effects of glyphosate

There are conflicting reports on the effect of potassium phosphite with or without glyphosate in plants. Some of them indicate that potassium phosphite may cause injuries when applied alone, while others point out that it can reduce the injury caused by glyphosate, when applied in association with this herbicide. This study aimed at evaluating the effect of potassium phosphite alone or in association with glyphosate on visual injury, dry matter accumulation, phytotoxicity indicator compounds levels and aromatic amino acid contents in maize plants. Treatments consisted of isolated or associated application of two glyphosate doses (72 $\mathrm{g} \mathrm{ha}^{-1}$ and $720 \mathrm{~g} \mathrm{ha}^{-1}$ ) and one potassium phosphite dose (Fosway - $3 \mathrm{~L} \mathrm{ha}^{-1}$ ). The visual evaluations of injury and harvesting were performed at 2, 4, 10 and 15 days after application. The potassium phosphite applied alone did not cause injury to plants, and its association with glyphosate, regardless of the dose tested, did not protect the plants against the injury and dry mass reduction caused by the herbicide. There was an accumulation of shikimic and quinic acids on the plants subjected to the highest dose of glyphosate with or without phosphite. The potassium phosphite treatments with or without glyphosate showed higher tryptophan levels and did not alter the phenylalanine and tyrosine contents in the plants.
\end{abstract}

KEY-WORDS: Zea mays; shikimic acid; quinic acid; aromatic amino acids.

\section{INTRODUÇÃO}

A maioria dos herbicidas inibe uma proteína ou enzima nas plantas (Cole et al. 2000). O sítio de ação do glyphosate é a enzima EPSPS (5-enolpiruvilchiquimato 3-fosfato sintase, E.C. 2.5.1.19), que catalisa a reação na qual o chiquimato-3-fosfato $(\mathrm{S} 3 \mathrm{P})$ reage com o fosfoenolpiruvato (PEP), formando 5-enolpiruvilchiquimato 3-fosfato (EPSP) e fósforo inorgânico (Pi) (Franz et al. 1997). A inibição

\section{RESUMO}

Existem relatos controversos sobre o efeito do fosfito de potássio, associado ou não ao glyphosate, em plantas. Alguns indicam que o fosfito de potássio pode causar injúrias, quando aplicado isoladamente, enquanto outros destacam que ele pode reduzir a injúria causada pelo glyphosate, quando aplicado em conjunto com este herbicida. Este estudo objetivou avaliar o efeito do fosfito de potássio, em associação ou não com o glyphosate, sobre a injúria visual, acúmulo de massa seca, níveis de compostos indicadores de fitotoxicidade e teores de aminoácidos aromáticos, em plantas de milho. Os tratamentos consistiram na aplicação isolada ou em associação de duas doses de glyphosate ( $72 \mathrm{~g} \mathrm{ha}^{-1}$ e $\left.720 \mathrm{~g} \mathrm{ha}^{-1}\right)$ e uma de fosfito de potássio (Fosway - $3 \mathrm{~L} \mathrm{ha}^{-1}$ ). As avaliações visuais de injúria e coletas de material vegetal foram realizadas aos 2, 4, 10 e 15 dias após a aplicação. O fosfito de potássio aplicado isoladamente não ocasionou injúrias às plantas e a sua associação com o glyphosate, independentemente da dose testada, não protegeu as plantas contra a injúria e a redução de massa seca causada pelo herbicida. Houve acúmulo dos ácidos chiquímico e quínico nas plantas submetidas à maior dose de glyphosate associada ou não ao fosfito. $\mathrm{O}$ fosfito de potássio, associado ou não ao glyphosate, promoveu maiores teores de triptofano e não alterou os teores de fenilalanina e tirosina nas plantas.

PALAVRAS-CHAVE: Zea mays; ácido chiquímico; ácido quínico; aminoácidos aromáticos.

da enzima EPSPS, afeta a rota metabólica do ácido chiquímico, a qual produz os aminoácidos aromáticos fenilalanina, tirosina e triptofano. Além disso, essa rota é responsável pela formação de compostos fenólicos, que podem representar até $35 \%$ da biomassa vegetal (Boudet et al. 1985).

O glyphosate é um dos herbicidas mais utilizados no mundo, devido, principalmente, ao seu amplo espectro de ação. Uma das principais alterações metabólicas decorrentes da exposição ao glyphosate nas 
plantas é o acúmulo de ácido chiquímico (Harring et al. 1998, Singh \& Shaner 1998, María et al. 2006, Buehring et al. 2007, Nandula et al. 2007, Petersen et al. 2007, Matallo et al. 2009, Orcaray et al. 2010, Reddy et al. 2010, Zelaya et al. 2011, Franco et al. 2012). Os elevados níveis de ácido chiquímico são utilizados como indicador precoce e altamente sensível dos efeitos do glyphosate nos tecidos das plantas (Harring et al. 1998). O ácido quínico, composto de estrutura semelhante à do ácido chiquímico, também pode ser acumulado em plantas expostas ao glyphosate (Orcaray et al. 2010 e 2012, Carbonari et al. 2014).

Há relatos de um possível efeito do fosfito na redução da intoxicação de algumas culturas, quando aplicado em conjunto com o herbicida glyphosate. A hipótese para esse efeito protetor é a de que o glyphosate e o fosfito podem competir pelas proteínas carregadoras de fosfato, que são responsáveis pela absorção de fosfato e estão presentes na membrana da célula (Morin et al. 1997). No entanto, Lucas et al. (1979) observaram severa intoxicação em plantas de milho, quando tratadas com fosfito, sendo que as injúrias foram muito semelhantes àquelas causadas pelo glyphosate. Esse fato pode ser explicado por Mitchell \& Adams (2004), os quais afirmam que o glyphosate possui um grupo fosfito em sua fórmula estrutural e, dessa maneira, o fosfito poderia ter causado injúria às plantas.

Diante dos relatos controversos do efeito do fosfito, este estudo objetivou avaliar o efeito do fosfito de potássio, em associação ou não com o glyphosate, em plantas de milho. $\mathrm{O}$ efeito foi avaliado quanto a injúrias visuais, acúmulo de massa seca, níveis de compostos indicadores de fitotoxicidade e teores de aminoácidos aromáticos.

\section{MATERIAL E MÉTODOS}

O experimento foi conduzido no Núcleo de Pesquisas Avançadas em Matologia da Faculdade de Ciências Agronômicas da Universidade Estadual Paulista (Unesp), em Botucatu (SP), em 2011. Foi utilizado delineamento experimental inteiramente casualizado, com seis tratamentos e quatro repetições. O híbrido simples de milho $30 \mathrm{~F} 53 \mathrm{H}$ foi cultivado em vasos com capacidade de 5 litros (uma planta por vaso), contendo substrato Bioplant (material orgânico de origem vegetal e vermiculita expandida) com $\mathrm{pH} 5,7( \pm 0,5)$.
Os tratamentos testados foram: glyphosate a $72 \mathrm{~g} \mathrm{ha}^{-1}$, glyphosate a $720 \mathrm{~g} \mathrm{ha}^{-1}$, glyphosate a $72 \mathrm{~g} \mathrm{ha}^{-1}+$ fosfito de potássio a $3 \mathrm{~L} \mathrm{ha}^{-1}$, glyphosate a $720 \mathrm{~g} \mathrm{ha}^{-1}+$ fosfito de potássio a $3 \mathrm{~L} \mathrm{ha}^{-1}$, fosfito a $3 \mathrm{~L} \mathrm{ha}^{-1}$ e um tratamento testemunha sem a aplicação de fosfito ou glyphosate. A composição do fosfito de potássio (Fosway) utilizado foi $30 \%$ de $\mathrm{P}_{2} \mathrm{O}_{5}$ e $20 \%$ de $\mathrm{K}_{2} \mathrm{O}$.

Aos 23 dias após a semeadura, quando as plantas de milho apresentavam cerca de 4 folhas totalmente expandidas, foi realizada a aplicação do herbicida com ou sem fosfito de potássio. Foi utilizado um pulverizador em ambiente controlado, com barra de pulverização equipada com quatro pontas XR 11002 vs, espaçadas em $0,5 \mathrm{~m}$ entre si e dispostas a $0,5 \mathrm{~m}$ de altura, em relação às plantas de milho. A pressão de trabalho utilizada pelo equipamento foi de $2,0 \mathrm{kgf} \mathrm{cm}^{-2}$, com velocidade de $3,6 \mathrm{~km} \mathrm{~h}^{-1}$ e consumo de calda de $200 \mathrm{~L} \mathrm{ha}^{-1}$. No momento da aplicação, a temperatura era de $24^{\circ} \mathrm{C}$ e a umidade relativa do ar de $67 \%$.

As coletas do material vegetal foram realizadas aos 15 dias após a aplicação (DAA), para quantificação dos aminoácidos aromáticos (fenilalanina, tirosina e triptofano), e aos 2, 4, 10 e 15 DAA, para quantificação dos níveis de ácido chiquímico e quínico. Para cada período, foram coletadas todas as folhas de uma planta de milho por repetição, as quais foram lavadas duas vezes com três litros de água destilada, em um recipiente plástico, para total remoção dos resíduos de glyphosate e fosfito que não foram absorvidos. Após a lavagem, as folhas foram acondicionadas em sacos de papel para secagem em estufa de circulação forçada de ar a $45^{\circ} \mathrm{C}$, por um período de 72 horas.

Para as análises dos compostos, o material vegetal coletado foi macerado em almofariz com nitrogênio líquido. Uma alíquota de $100 \mathrm{mg}$ da amostra moída foi acondicionada em tubo de centrífuga com $10 \mathrm{~mL}$ de água acidificada a pH 2,5 (Matallo et al. 2009). Em seguida, os tubos foram submetidos a banho de ultrassom, com frequência ultrassônica de $42 \mathrm{KHz}$, durante 30 minutos, e centrifugados a $4.000 \mathrm{~g}$, durante 10 minutos, a $20^{\circ} \mathrm{C}$. O sobrenadante foi coletado e filtrado em filtro Millex HV $0,45 \mu \mathrm{m}$, com membrana durapore de $13 \mathrm{~mm}$, e acondicionado em vial âmbar, para quantificação dos compostos por cromatografia líquida acoplada à espectrometria de massas (LC-MS/MS).

Aos 2, 4, 10 e 15 DAA também foram realizadas avaliações visuais de intoxicação das plantas, 
seguindo-se uma escala percentual na qual " 0 " significa ausência de sintomas visuais de intoxicação e "100" a morte da planta. Aos 15 DAA, foi realizada a coleta da parte aérea das plantas, para determinação da massa, após secagem em estufa com circulação forçada de ar a $60{ }^{\circ} \mathrm{C}$, durante 72 horas.

Os dados de injúria visual, massa seca e teores de aminoácidos foram submetidos à análise de variância, pelo teste $\mathrm{F}$, e as médias comparadas pelo teste Tukey $(\mathrm{p} \leq 0,05)$. Os valores de ácido chiquímico e quínico nas plantas tratadas foram divididos pelos valores obtidos desses compostos na testemunha sem aplicação, para obtenção de uma relação entre tratamento e testemunha.

\section{RESULTADOS E DISCUSSÃO}

As plantas de milho apresentaram níveis de intoxicação superiores a $74 \%$, após 10 dias da aplicação, quando submetidas à dose de $720 \mathrm{~g} \mathrm{ha}^{-1}$ de glyphosate isolado e em associação com fosfito (Tabela 1). A associação do fosfito com a maior dose de glyphosate reduziu os níveis de injúria visual em $60 \%, 31 \%$ e $5 \%$, respectivamente aos 2, 4 e 15 DAA, em comparação com a aplicação dessa dose de glyphosate isoladamente. Aos $15 \mathrm{DAA}$, a intoxicação das plantas submetidas à menor dose de glyphosate isolado foi cerca de $48 \%$ menor do que a daquelas em que foi aplicado glyphosate associado ao fosfito. O fosfito de potássio aplicado isoladamente não ocasionou nenhum sintoma de intoxicação.

Houve redução no acúmulo de massa seca das plantas em função da dose de glyphosate aplicada, ou seja, quanto maior a dose, maior a redução. No entanto, a aplicação do fosfito de potássio isolada- mente e em associação com o glyphosate não provocou nenhum efeito no acúmulo de massa seca das plantas (Tabela 1).

Houve acúmulo de cerca de 20 vezes no teor de ácido chiquímico, nas plantas de milho tratadas com a maior dose de glyphosate aos 2 DAA, sendo que os maiores níveis foram encontrados nas plantas submetidas à dose de $720 \mathrm{~g} \mathrm{ha}^{-1}$ associada ao fosfito de potássio aos $10 \mathrm{DAA}$, com concentrações cerca de 120 vezes maiores do que na testemunha (Figura 1a).

As plantas que receberam a menor dose de glyphosate também apresentaram aumento de até 15 vezes no teor de ácido chiquímico, quando associada ao fosfito, e de 4 vezes, quando aplicada isoladamente aos 4 DAA, sendo esses acúmulos muito menores do que aqueles observados com a aplicação de $720 \mathrm{~g} \mathrm{ha}^{-1}$ de glyphosate. De forma semelhante ao observado para a injúria visual, foram constatados maiores níveis de ácido chiquímico nas plantas que receberam a dose de $72 \mathrm{~g} \mathrm{ha}^{-1}$ associada ao fosfito, quando comparadas com as que foram tratadas somente com glyphosate.

O aumento da concentração de ácido chiquímico ocorre com o bloqueio da enzima EPSPS pelo glyphosate, conforme observado em plantas de milho não resistentes ao glyphosate (Reddy et al. 2010), plântulas de Brassica napus (Petersen et al. 2007), folhas de ervilha (Orcaray et al. 2010), folhas de B. decumbens e cana-de-açúcar (Matallo et al. 2009) e folhas jovens e maduras de Lupinus albus (María et al. 2006).

Após 4 DAA, houve queda nos teores de ácido chiquímico nas plantas tratadas com a dose de $72 \mathrm{~g} \mathrm{ha}^{-1}$, alcançando o nível encontrado na testemunha no último período avaliado, independente-

Tabela 1. Porcentagem de intoxicação (2, 4, 10 e 15 DAA) e massa seca da parte aérea de híbridos de milho aos 21 DAA (Botucatu, SP, 2011).

\begin{tabular}{|c|c|c|c|c|c|}
\hline \multirow{2}{*}{ Tratamentos } & \multicolumn{4}{|c|}{ Dias após o tratamento (DAA) } & \multirow{2}{*}{$\begin{array}{c}\text { Massa seca } \\
\text { (g) }\end{array}$} \\
\hline & 2 & 4 & 10 & 15 & \\
\hline Testemunha & $0 \mathrm{c}$ & $0 \mathrm{~d}$ & $0 \mathrm{~d}$ & $0 \mathrm{e}$ & $2,50 \mathrm{a}$ \\
\hline Glyphosate $\left(72 \mathrm{~g} \mathrm{ha}^{-1}\right)$ & $0 \mathrm{c}$ & $4 \mathrm{c}$ & $25 \mathrm{c}$ & $29 \mathrm{~d}$ & $1,90 \mathrm{~b}$ \\
\hline Glyphosate $\left(720 \mathrm{~g} \mathrm{ha}^{-1}\right)$ & $5 \mathrm{a}$ & $22 \mathrm{a}$ & $75 \mathrm{a}$ & $89 \mathrm{a}$ & $1,20 \mathrm{c}$ \\
\hline Glyphosate $\left(72 \mathrm{~g} \mathrm{ha}^{-1}\right)+$ fosfito & $0 \mathrm{c}$ & $5 \mathrm{c}$ & $33 \mathrm{~b}$ & $43 \mathrm{c}$ & $1,90 \mathrm{~b}$ \\
\hline Glyphosate $\left(720 \mathrm{~g} \mathrm{ha}^{-1}\right)+$ fosfito & $2 \mathrm{~b}$ & $15 \mathrm{~b}$ & $74 \mathrm{a}$ & $84 \mathrm{~b}$ & $1,30 \mathrm{c}$ \\
\hline Fosfito & $0 \mathrm{c}$ & $0 \mathrm{~d}$ & $0 \mathrm{~d}$ & $0 \mathrm{e}$ & $2,60 \mathrm{a}$ \\
\hline F tratamento & $150,00 * *$ & $196,10 * *$ & $1.616,70 * *$ & $1.350,60 * *$ & $43,70 * *$ \\
\hline CV $(\%)$ & 28,27 & 16,30 & 4,89 & 5,23 & 15,33 \\
\hline DMS & 0,49 & 1,83 & 2,48 & 3,15 & 0,25 \\
\hline
\end{tabular}

** Significativo a $1 \%$, pelo teste $\mathrm{F}$ ( $\mathrm{p} \geq 0,01$ ). Médias seguidas da mesma letra, na coluna, não diferiram significativamente pelo teste Tukey ( $\mathrm{p} \geq 0,05$ ). 
mente da associação com o fosfito de potássio. Aos 15 DAA, também ocorreu redução nos teores de ácido chiquímico para 47 e 66 vezes, em relação à testemunha, para os tratamentos com a maior dose de glyphosate isolada e associada ao fosfito, respectivamente (Figura 1). Os níveis de ácido chiquímico, após a aplicação do glyphosate, podem mudar com o tempo, como observado em grãos de Triticum aestivum (Bresnahan et al. 2003) e folhas de Conyza canadensis (Müller et al. 2003).

Os teores de ácido quínico também foram alterados nas plantas de milho após a aplicação de glyphosate, principalmente na maior dose testada (Figura 1b). O maior nível de ácido quínico nas plantas tratadas foi observado aos 4 DAA, sendo superior naquelas submetidas à dose de $720 \mathrm{~g} \mathrm{ha}^{-1}$ de glyphosate aplicada isoladamente, com concen-

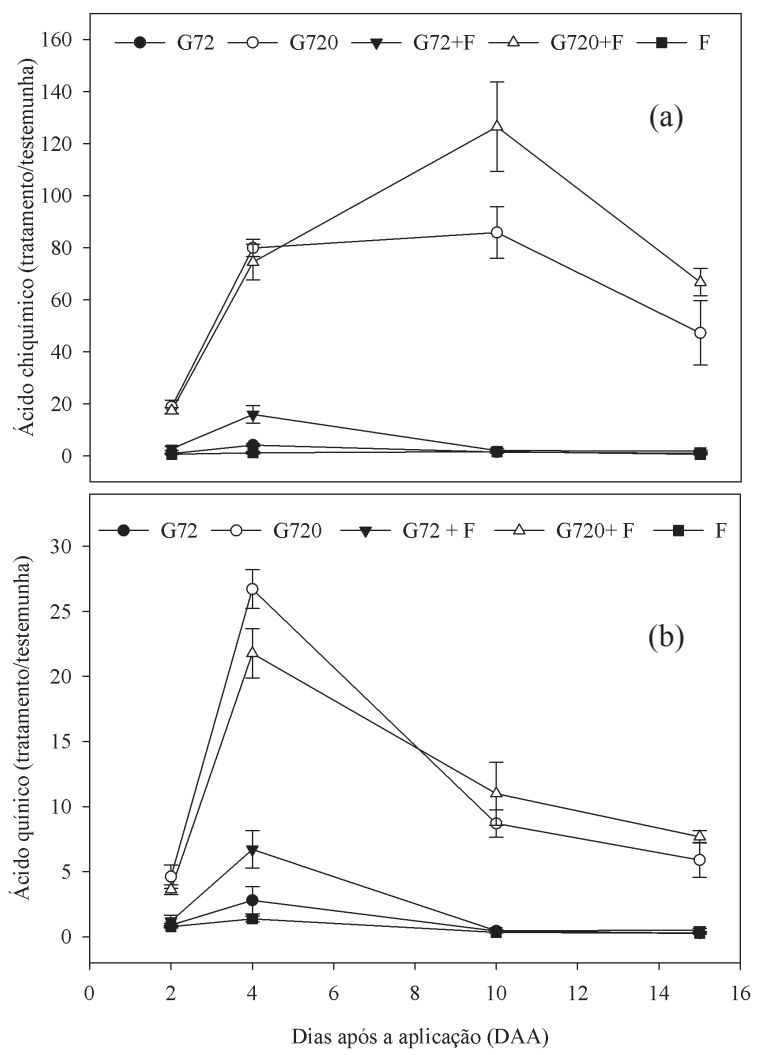

Figura 1. Razão para os teores de ácidos fenólicos (ácido chiquímico - a e quínico - b) encontrados em plantas de milho tratadas e não tratadas com glyphosate e/ ou fosfito, após diferentes períodos de exposição aos tratamentos (Botucatu, SP, 2011). Cada valor corresponde à média \pm erro padrão $(n=4)$. G $72=$ glyphosate $72 \mathrm{~g} \mathrm{ha}^{-1}$; G 720 = glyphosate $720 \mathrm{~g} \mathrm{ha}^{-1}$; $\mathrm{G} 72+\mathrm{F}=$ glyphosate $72 \mathrm{~g} \mathrm{ha}^{-1}+$ fosfito; $\mathrm{G} 720+\mathrm{F}=$ glyphosate $720 \mathrm{~g} \mathrm{ha}^{-1}+$ fosfito; $\mathrm{F}=$ fosfito. trações até 25 vezes maiores do que na testemunha. Esse acúmulo pode estar relacionado ao aumento no fluxo de carbono na direção da síntese do ácido quínico, decorrente da aplicação do glyphosate, como observado por Ossipov \& Aleksandrova (1982), em acículas de pinheiro.

O ácido quínico também acumulou cerca de 1,$4 ; 2,4 ;$ e 1,6 vezes mais, em relação à testemunha, em folhas de ervilha (Pisum sativum L. cv. Sugar Boys) tratadas com glyphosate, imazethapyr e chlorsulfuron, respectivamente, aos 15 dias após os tratamentos. O aumento de ácido quínico após o tratamento com glyphosate deve-se ao acúmulo de compostos formados anteriormente ao passo biosintético catalisado pela EPSPS, como ocorre para os ácidos chiquímico, protocatecúico e gálico (Orcaray et al. 2010).

A associação do glyphosate com o fosfito promoveu um pequeno aumento nos níveis dos aminoácidos aromáticos, em relação à aplicação isolada do herbicida aos 15 DAA, embora esse aumento não tenha sido significativo (Figura 2). A dose de $720 \mathrm{~g} \mathrm{ha}^{-1}$ de glyphosate, associada ou não ao fosfito, reduziu os níveis de fenilalanina e tirosina, em comparação com a testemunha, no entanto, não alterou os níveis de triptofano.

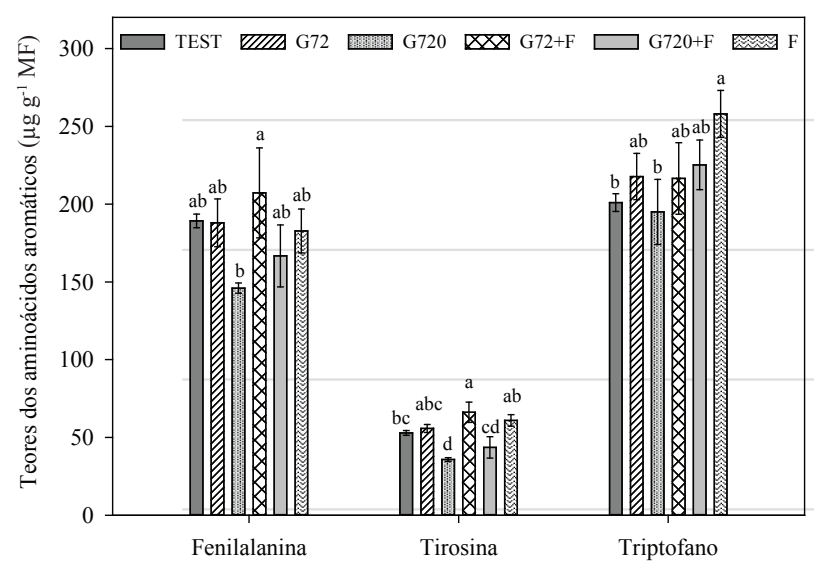

Figura 2. Teores dos aminoácidos aromáticos fenilalanina, tirosina e triptofano, em plantas de milho, aos 15 DAA, tratadas com glyphosate e fosfito isoladamente ou em associação (Botucatu, SP, 2011). Cada valor corresponde à média \pm erro padrão $(\mathrm{n}=4)$. TEST $=$ testemunha; GL $72=$ glyphosate $72 \mathrm{~g} \mathrm{ha}^{-1}$; GL $720=$ glyphosate $720 \mathrm{~g} \mathrm{ha}^{-1}$; GL $72+\mathrm{F}=$ glyphosate $72 \mathrm{~g} \mathrm{ha}^{-1}+$ fosfito; GL $720+\mathrm{F}=$ glyphosate $720 \mathrm{~g} \mathrm{ha}^{-1}+$ fosfito; $\mathrm{F}=$ fosfito. Fenilalanina: Ftrat $=$ $1,577^{\text {ns }}, C V=18,69 \%$ e DMS $=19,98$. Tirosina: Ftrat $=6,630 * *, C V=16,57 \%$ e DMS $=12,93$. Tirosina: Ftrat $=1,743^{\text {ns }}, C V=15,37 \%$ e DMS $=$ 49,99 . ${ }^{\text {ns }}$ não significativo; $* *$ significativo a $1 \%$. 
O fosfito de potássio aplicado isoladamente foi responsável por aumento significativo nos níveis de triptofano, sendo o possível responsável pelo aumento deste aminoácido nas plantas tratadas com glyphosate na maior dose associada ao fosfito. Amrhein et al. (1980) sugerem que o triptofano é o aminoácido aromático menos sensível à inibição pelo glyphosate. Wang et al. (2001) relataram aumento na concentração de triptofano aos 3 dias após a aplicação de glyphosate em plântulas de Cyperus rotundus, em relação à testemunha.

Os níveis dos aminoácidos aromáticos não se alteraram ou foram maiores que na testemunha, nas plantas submetidas à aplicação de glyphosate na menor dose $\left(72 \mathrm{~g} \mathrm{ha}^{-1}\right)$, e a associação desta dose com o fosfito promoveu aumento nos níveis de tirosina, com relação à testemunha não tratada. Petersen et al. (2007) verificaram aumento pronunciado na concentração de fenilalanina em plantas de B. napus, em resposta às concentrações de $1 \mu \mathrm{M}$ e $10 \mu \mathrm{M}$ de glyphosate, mas a concentração tende a decrescer até a exposição a $50 \mu \mathrm{M}$ de glyphosate, estando pouco abaixo da concentração encontrada na testemunha.

Embora o glyphosate seja responsável pelo bloqueio da biossíntese dos aminoácidos aromáticos, os resultados observados no presente estudo não revelam um claro decréscimo no conteúdo de fenilalanina, tirosina e triptofano, quando suas concentrações em plantas expostas ao glyphosate são comparadas com as concentrações das plantas testemunhas. Esse aumento no teor de aminoácidos também foi observado por outros autores (Wang et al. 2001, Petersen et al. 2007, Gravena et al. 2009, Orcaray et al. 2010) e pode estar relacionado com a degradação das proteínas das plantas e a consequente liberação dos aminoácidos que compõem as mesmas. Gravena et al. (2009) verificaram efeito transitório do glyphosate nos teores de aminoácidos totais, com redução aos 2 DAT, em folhas jovens e maduras de limão cravo submetidas a diferentes doses de glyphosate. Esses mesmos autores observaram que, a partir de 4 DAT, houve aumento nos níveis dos aminoácidos, independentemente da dose de glyphosate testada.

No presente trabalho, observou-se que a aplicação de fosfito, isoladamente ou associado ao glyphosate, não promoveu nenhum efeito nas plantas de milho. Assim, com base nesses resultados, não se recomenda a utilização de fosfito para a redução dos efeitos fitotóxicos ocasionados pelo glyphosate, em plantas de milho.

\section{CONCLUSÕES}

1. O fosfito de potássio aplicado isoladamente não ocasiona injúrias às plantas, e a sua associação com o glyphosate, independentemente da dose testada, não protege as plantas contra a injúria e a redução de massa seca causada pelo herbicida.

2. Os ácidos chiquímico e quínico se acumulam nas plantas submetidas a altas doses de glyphosate, associadas ou não ao fosfito, estando de acordo com a intoxicação visual das plantas causada por esse herbicida.

3. Tanto o glyphosate como o fosfito promovem poucas alterações na concentração dos aminoácidos aromáticos, aos 15 dias após a aplicação.

\section{REFERÊNCIAS}

AMRHEIN, N. et al. The site of the inhibition of the shikimate pathway by glyphosate: II. Interference of glyphosate with chorismate formation in vivo and in vitro. Plant Physiology, Rockville, v. 66, n. 5, p. 830-834, 1980.

BOUDET, A. M. et al. Recent advances in the regulation of the prearomatic pathway. In: VAN SUMERE, C. F.; LEA, P. J. (Eds.). Annual Proceedings of the Phytochemical Society of Europe, Oxford, v. 25, n. 1, p. 135-159, 1985.

BRESNAHAN, G. A. et al. Glyphosate applied preharvest induces shikimic acid accumulation in hard red spring wheat (Triticum aestivum). Journal of Agricultural and Food Chemistry, Washington, DC, v. 51, n. 14, p. 40044007, 2003.

BUEHRING, N. W. et al. Shikimic acid accumulation in field-grown corn (Zea mays) following simulated glyphosate drift. Journal of Agricultural and Food Chemistry, Washington, DC, v. 55, n. 3, p. 819-824, 2007.

CARBONARI, C. A. et al. Glyphosate effects on sugarcane metabolism and growth. American Journal of Plant Sciences, Irvine, v. 5, n. 24, p. 3585-3593, 2014.

COLE, D. et al. Discovering new modes of action for herbicides and the impact of genomics. Pesticide Outlook, New York, v. 11, n. 6, p. 223-229, 2000.

FRANCO, D. A. S. et al. Evaluation of glyphosate application on transgenic soybean and its relationship with shikimic acid. Planta Daninha, Viçosa, v. 30, n. 3, p. 659-666, 2012.

FRANZ, J. E. et al. Glyphosate: a unique global herbicide. Washington, DC: American Chemical Society, 1997.

GRAVENA, R. et al. Low glyphosate rates do not affect Citrus limonia (L.) Osbeck seedlings. Pest Management Science, New York, v. 65, n. 4, p. 420-425, 2009. 
HARRING, T. et al. Accumulation of shikimic acid: a technique for screening glyphosate efficiency. Journal of Agricultural and Food Chemistry, Washington, DC, v. 46, n. 10 , p. $4406-4412,1998$.

LUCAS, R. E. et al. Phosphite injury to corn. Agronomy Journal, Madison, v. 71, n. 6, p. 1063-1065, 1979.

MARÍA, N. et al. New insights on glyphosate mode of action in nodular metabolism: role of shikimate accumulation. Journal of Agricultural and Food Chemistry, Washington, DC, v. 54, n. 7, p. 2621-2628, 2006.

MATALLO, M. B. et al. Microwave-assisted solvent extraction and analysis of shikimic acid from plant tissues. Planta Daninha, Viçosa, v. 27, n. esp., p. 987-994, 2009.

MITCHELL, C.; ADAMS, J. Phosphites as fertilizer. 2004. Disponível em: <http://www.aces.edu/timelyinfo/ Ag\%20Soil/2004/May/s-04-04-phosphite.pdf>. Acesso em: 14 abr. 2014.

MORIN, F. et al. Glyphosate uptake in Catharanthus roseus cells: role of a phosphate transporter. Pesticide Biochemistry and Physiology, San Diego, v. 58, n. 1, p. 13-22, 1997.

MÜELLER, T. C. et al. Shikimate accumulates in both glyphosate-sensitive and glyphosate-resistant horseweed (Conyza Canadensis L. Cronq.). Journal of Agricultural and Food Chemistry, Washington, DC, v. 51, n. 3, p. 680684, 2003.

NANDULA, M. N. et al. Glyphosate-resistant and -susceptible soybean (Glycine max) and canola (Brassica napus) dose response and metabolism relationships with glyphosate. Journal of Agricultural and Food Chemistry, Washington, DC, v. 55, n. 9, p. 3540-3545, 2007.
ORCARAY, L. et al. Impairment of carbon metabolism induced by the herbicide glyphosate. Journal of Plant Physiology, Toronto, v. 169, n. 1, p. 27-33, 2012.

ORCARAY, L. et al. The possible role of quinate in the mode of action of glyphosate and acetolactate synthase inhibitors. Pest Management Science, New York, v. 66, n. 3, p. 262-269, 2010.

OSSIPOV, V. I.; ALEKSANDROVA, L. P. Spatial organization of quinic and shikimic acid biosynthesis in autotrophic cells of Pinus sylvestris needles. Soviet Plant Physiology, New York, v. 29, n. 3, p. 289-292, 1982.

PETERSEN, I. L. et al. Metabolic effects in rapeseed (Brassica napus L.) seedlings after root exposure to glyphosate. Pesticide Biochemistry and Physiology, San Diego, v. 89, n. 3, p. 220-229, 2007.

REDDY, K. N. et al. Glyphosate effect on shikimate, nitrate reductase activity, yield, and seed composition in corn. Journal of Agricultural and Food Chemistry, Washington, DC, v. 58, n. 6, p. 3646-3650, 2010.

SINGH, B. K.; SHANER, D. L. Rapid determination of glyphosate injury to plants and identification of glyphosate-resistant plants. Weed Technology, Champaign, v. 12, n. 3, p. 527-530, 1998.

WANG, C. Y. et al. Effect of glyphosate on aromatic amino acid metabolism in purple nutsedge (Cyperus rotundus). Weed Technology, Champaign, v. 15, n. 4, p. 628-635, 2001.

ZELAYA, I. A. et al. Evaluation of spectrophotometric and hplc methods for shikimic acid determination in plants: models in glyphosate-resistant and -susceptible crops. Journal of Agricultural and Food Chemistry, Washington, DC, v. 59, n. 6, p. 2202-2212, 2011. 